07

\title{
Эволюция дефектной структуры при испытаниях в режиме ползучести ультрамелкозернистых металлов и сплавов, полученных методами интенсивной пластической деформации
}

\author{
(C) В.И. Бетехтин, А.Г. Кадомцев, М.В. Нарыкова
}

Физико-технический институт им. А.Ф. Иофрфе РАН,

Санкт-Петербург, Россия

ฯ E-mail: Maria.Narykova@mail.ioffe.ru

Поступила в Редакцию 2 октября 2019 г.

В окончательной редакции 2 октября 2019 г.

Принята к публикации 2 октября 2019 г.

\begin{abstract}
Методами малоуглового рентгеновского рассеяния, электронной микроскопии и измерения плотности выявлены структурные факторы, ведущие к снижению механостабильности ультрамелкозернистых (УМЗ) металлов и сплавов при их испытании в режиме ползучести при повышенных температурах. Установлено, что одним из важных факторов являются нанопоры, образовавшиеся при интенсивной пластической деформации. Развитие этих нанопор, в формирующихся в процессе ползучести границ зерен, реализуется диффузионным механизмом и ведет к разрушению. Рассмотрена роль дисперсных включений и большеугловых границ зерен для прочности УМЗ-металлов и сплавов при их „кратковременном“ и длительном нагружении.
\end{abstract}

Ключевые слова: ползучесть, долговечность, нанопоры, ультрамелкозернистые металлы, сплавы.

DOI: 10.21883/FTT.2020.02.48878.603

\section{1. Введение}

Выявление особенностей дефектной структуры и механических свойств ультрамелкозернистых (УМЗ) металлов и сплавов, полученных методами интенсивных пластических деформаций (ИПД), является одним из перспективных направлений современного материаловедения [1-4]. В процессе ИПД формируются те особенности дефектной структур (ультраразмерные зерна с высокой разориентацией; повышенная плотность дислокаций; вакансий и их комплексов - нанопор, локализующихся, в основном, в границах зерен), которые и определяют высокие механические свойства УМЗ-металлических материалов. При этом отмеченные особенности дефектной структуры могут по-разному влиять на механические свойства при кратковременном (предел прочности и текучести, микротвердость) и длительном (долговечность при ползучести и усталости) нагружении: рост предела прочности и микротвердости после ИПД может в ряде случаев сопровождаться снижением долговечности [5-8].

Действительно, полученные при ИПД металлические УМЗ-материалы (особенно их границы зерен) находятся в нестабильном, неравновесном состоянии [9-11] и при длительном механическом и тепловом воздействии могут терять свои высокие прочностные свойства. С учетом вышесказанного изучение эволюции дефектной структуры УМЗ-металлов и сплавов при длительном нагружении и повышенной температуры имеет важное значение для понимания физических механизмов деструктивных процессов, определяющих долговечность и, следовательно, эксплуатационный ресурс УМЗ-материалов.
В данной работе будет рассмотрено влияние эволюции дефектной структуры, особенно нанопористости, сформировавшейся при ИПД, на долговечность некоторых металлов и сплавов при их длительном испытании в режиме ползучести при повышенной температуре. При анализе вклада „исходной“ (образовавшейся после ИПД) нанопористости в долговечность предполагается также учесть результаты более ранних работ [11-15].

\section{2. Материал и методики измерения}

В качестве материала для исследования использовались в основном титан марки ВТ1-0, а также Al (99.99\%) и его сплав $\mathrm{Al}+0.2$ wt.\% Sc. Сплав $\mathrm{Al}$ после термообработки содержал частицы второй фазы $\mathrm{Al}_{3} \mathrm{Sc}$ размером $\approx 5-8 \mathrm{~nm}[5]$. ИПД проводилась двумя методами. Равноканальным угловым прессованием (РКУП) с разным числом проходов (от 1 до 12) и поворотом на 90 после каждого прохода, либо при комнатной температуре, либо (для титана) при $673 \mathrm{~K}$. Для титана использовалась также ИПД по отработанному в $[15,16]$ режиму винтовой и продольной прокатке (ВПП) при $673 \mathrm{~K}$.

Длительные нагружения УМЗ-металлов и сплавов проводились в режиме ползучести при постоянстве в процессе растяжения каждого образца напряжения и температуры $673 \mathrm{~K}$; при этой температуре проводились ранее испытания в режиме ползучести УМЗ-титана $[7,8,11]$ и имелась поэтому возможность сопоставительного анализа данных нашей работы с полученными ранее результатами. 
Определение плотности и ее изменение как после ИПД, так и после испытания в режиме ползучести проводилось с помощью прецизионного метода гидростатического взвешивания, относительная погрешность измерений не превышала $10^{-4}$. Наблюдаемое разуплотнение (после ИПД и после испытания в режиме ползучести) служило характеристикой интегрального объема повреждений, образовавшихся при деформации.

Модифицированным методом рентгеновского рассеяния (МРP) в области сверхмалых углов определялись размеры неоднородностей электронной плотности (поры и частицы второй фазы наноразмеров). Для идентификации природы этих неоднородностей и оценке после этого их концентрации изучались МРР и плотность до и после воздействия на образцы высокого $(\sim 1.5 \mathrm{GPa})$ гидростатического давления [5,17], которое интенсивно влияет именно на неоднородности пониженной плотности (нанопоры) за счет их залечивания.

Структурные исследования для определения размеров зерен проводились с помощью просвечивающей (Philips CM12) и сканирующей (JEOL 6466) электронной микроскопии с использованием обратного электронного рассеяния для измерения распределения зерен по разориентации.

Ряд структурных исследований и испытаний в режиме ползучести проводились в ИФМ (Брно, ЧР), с сотрудниками которого (V. Sklenicka, J. Dvorak, P. Kral и M. Svoboda) авторы вели совместные работы по изучению эволюции дефектной структуры в процессе ползучести крупнозернистых и УМЗ-металлов $[5,7,8,11,14,17-20]$.

\section{3. Экспериментальные данные и их обсуждения}

Прежде чем переходить к рассмотрению полученных в данной работе результатов отметим, что общие закономерности влияния ИПД при РКУП на ползучесть и долговечность ряда металлов и сплавов были детально изучены в работах V. Sklenicka et.al [18,21-24], a в [17] методом МРР и измерения плотности было впервые обнаружено образование при РКУП алюминия нанопор размером $\approx 15-25 \mathrm{~nm}$. Позднее, в [25] методом малоуглового нейтронного рассеяния и электронной микроскопии было также зафиксировано образование при РКУП титана нанопор размером в десятки нанометров. Наличие нанопор после разных методов ИПД в настоящее время выявлено в ряде работ [7,8,18,25-31].

В данной работе будут рассмотрены экспериментальные результаты исследований, подтверждающие роль нанопор, образовавшихся при ИПД, как одного из важных дефектов, снижающих долговечность УМЗ-металлов и сплавов при их длительном нагружении в режиме ползучести при повышенных температурах.

Наиболее детально была изучена эволюция повреждаемости, а также размера зерен в процессе испыта-

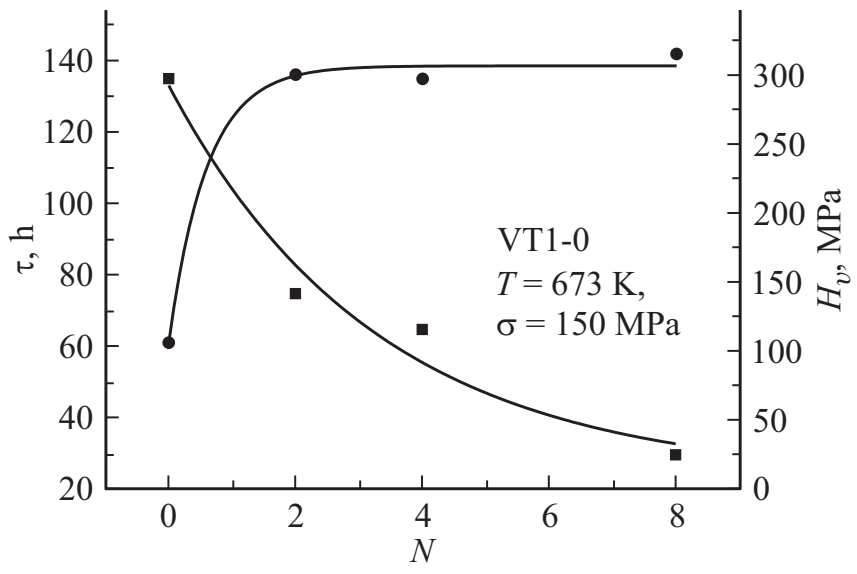

Рис. 1. Зависимость долговечности и микротвердости от числа проходов $N$ при РКУП для ВТ1-0.

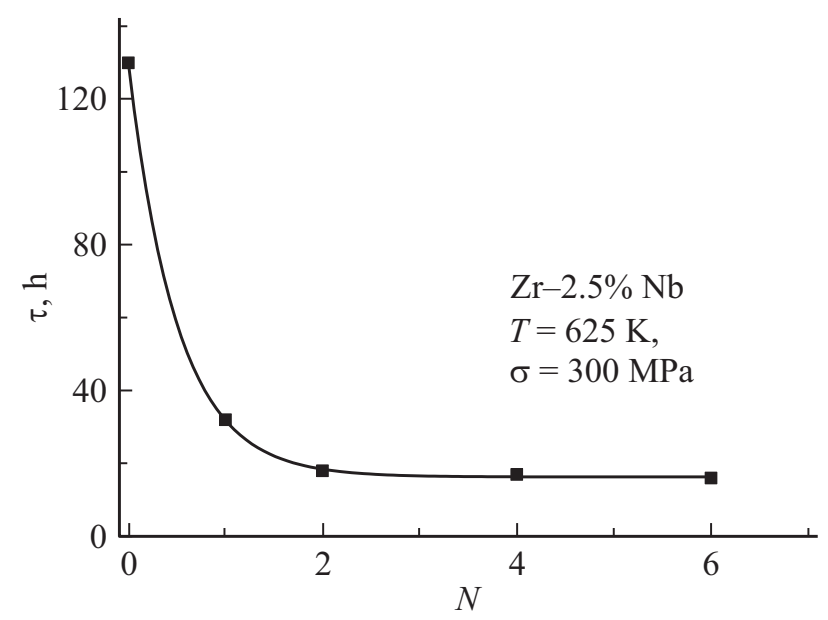

Рис. 2. Зависимость долговечности от числа проходов $N$ при РКУП для Zr-2.5\% Nb. Данные по Zr-2.5\% Nb из [6].

ния на долговечность в режиме ползучести образцов УМЗ-титана, приготовленных методами РКУП и ВПП. Уже при исследовании этих образцов ярко проявилось различное влияние ИПД на характеристики механических свойств УМЗ-титана при „кратковременном“ (микротвердость) и длительном (долговечность при ползучести) нагружении.

Последнее наглядно видно из данных рис. 1, на котором показана зависимость микротвердости и долговечности от степени ИПД (числа проходов при РКУП). Видно, что с ростом числа проходов микротвердость увеличивается (особенно резко после первых проходов), а долговечность УМЗ-титана непрерывно падает и уже после первых проходов становится даже меньше, чем для „исходного“ (до РКУП) крупнозернистого состояния.

Отметим, что негативное влияние числа проходов при РКУП на долговечность при высокотемпературной $(673 \mathrm{~K})$ ползучести наблюдалось также для сплава $\mathrm{Zr}+2.5 \% \mathrm{Nb}[6]$, рис. 2 . 


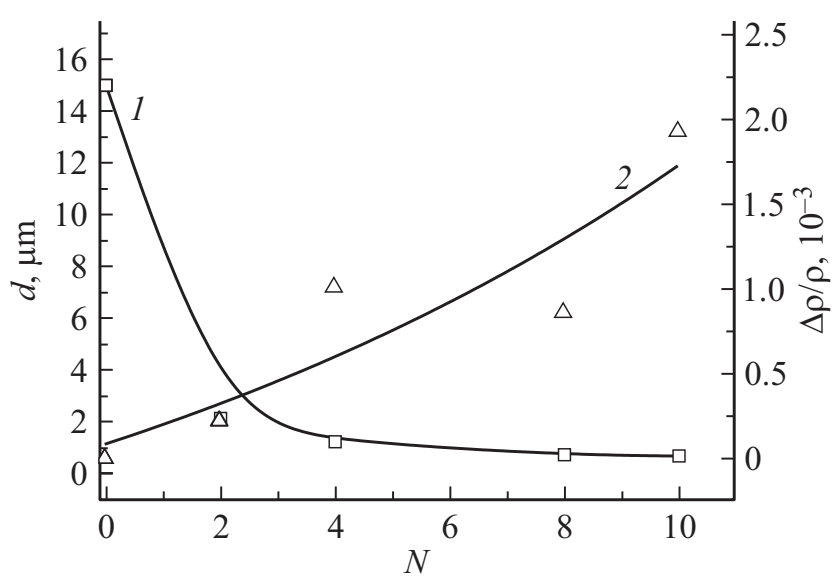

Рис. 3. Зависимость размера зерна $d(1)$ и величины разуплотнения $\Delta \rho / \rho(2)$ от числа проходов $N$ при РКУП для ВТ1-0.

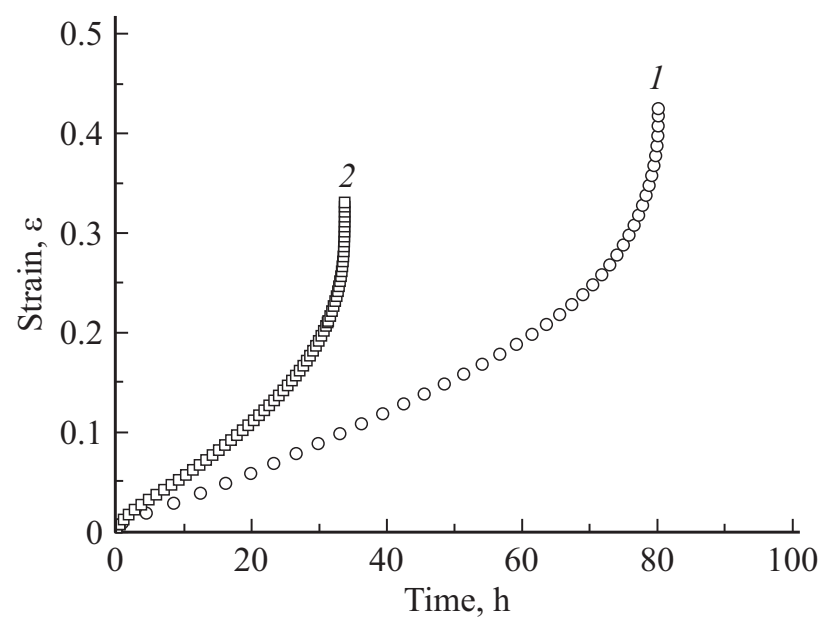

Рис. 4. Кривые ползучести ВТ1-0: 1 - после ВПП, 2 - после РКУП (8 проходов). Испытания выполнены при $T=673 \mathrm{~K}$ и $\sigma=150 \mathrm{MPa}$.

Рассмотрим возможные причины сложного влияния ИПД на механические свойства УМЗ-металлических материалов. На рис. 3 показана зависимость от числа проходов размера зерен и степени разуплотнения (относительного дефекта плотности) для тех же образцов УМЗ-титана, данные по которым были приведены на рис. 1. Из сравнения рис. 1. и 3 можно сделать вывод, что рост микротвердости обусловлен, очевидно, уменьшением размера зерен, а уменьшение долговечности коррелирует с увеличением после РКУП (до испытания на ползучесть) величины дефекта плотности. Связь долговечности с величиной образовавшегося при ИПД разуплотнения наглядно видно также из данных рис. 4. Так для образцов, приготовленных методом РКУП величина разуплотнения составляла $\approx 1.5 \cdot 10^{-3}$, а для приготовленных методом ВПП $\approx 6 \cdot 10^{-4}$. Видно, что чем меньше „исходное“ (после ИПД) разуплотнение, тем больше долговечность. Ранее было показано, что величина разуплотнения (относительный дефект плот- ности) после РКУП обусловлена, в основном, образованием нанопор размером в десятки нанометров [17]. Это позволило предполагать, что образующиеся при ИПД нанопоры (практически не влияя на прочность при „кратковременном“ нагружении), являются „очагами“ развития разрушения при длительном нагружении в условиях ползучести $[5,17]$.

Для подтверждения этого вывода в данной работе методами денситометрии, электронной микроскопии и МРP было проведено комплексное исследование эволюции при ползучести образцов УМЗ-титана как повреждаемости (общего объема разуплотнения, а также нано и микропористости), так и размера и разориентации зерен. Предполагалось, что анализ всех полученных данных позволит выявить физический механизм влияния „исходной“ (после ИПД) нанопористости на развитие разрушения и долговечность при длительном нагружении в исследованном режиме ползучести.

Рассмотрим типичные результаты комплексного исследования эволюции повреждаемости и параметров зеренной структуры в процессе ползучести образцов УМЗ-титана, полученного методом ВПП. Испытания в режиме ползучести проводились при $T=673 \mathrm{~K}$ и напряжениях $150 \mathrm{MPa}$ (рис. 4); в работе были также детально исследованы образцы, испытанные при $673 \mathrm{~K}$ и напряжениях 100 и $200 \mathrm{MPa}$.

Для этих образцов в „исходном“ (после РКУП) состоянии и после их испытания в указанном режиме ползучести (при долговечности $\approx 80$ часов), методом МРP была проведена оценка параметров нанопор.

На рис. 5 приведены зависимости интенсивности рассеяния I от угла рассеяния $\varphi$ для „исходных“ образцов и тех же образцов титана после их испытания на долговечность. Видно, что эти зависимости заметно отличаются: после испытания интенсивность рассеяния, связанная с концентрацией неоднородностей [32] существенно меньше.

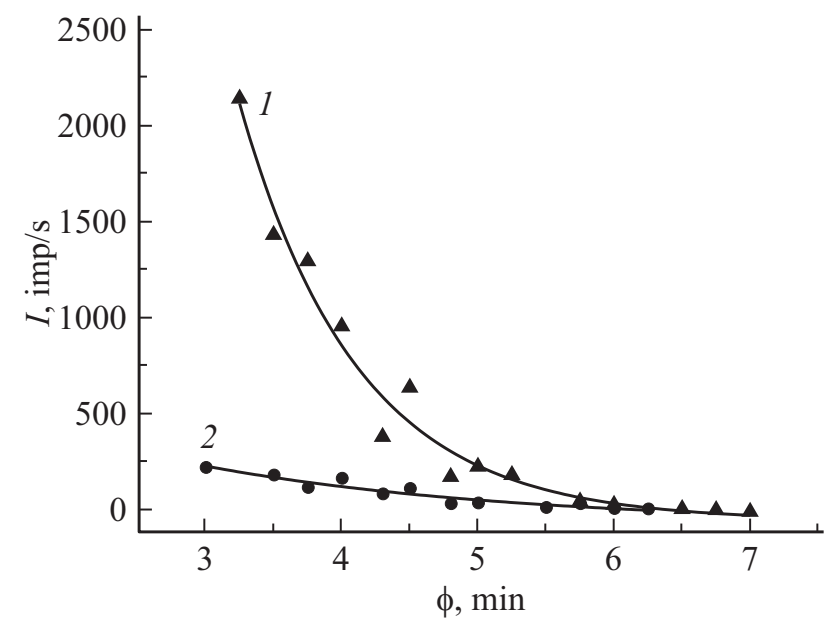

Рис. 5. Зависимость интенсивности I рентгеновских лучей от угла рассеяния $\varphi$ для УМЗ-титана до (1) и после (2) испытаний на ползучесть. 


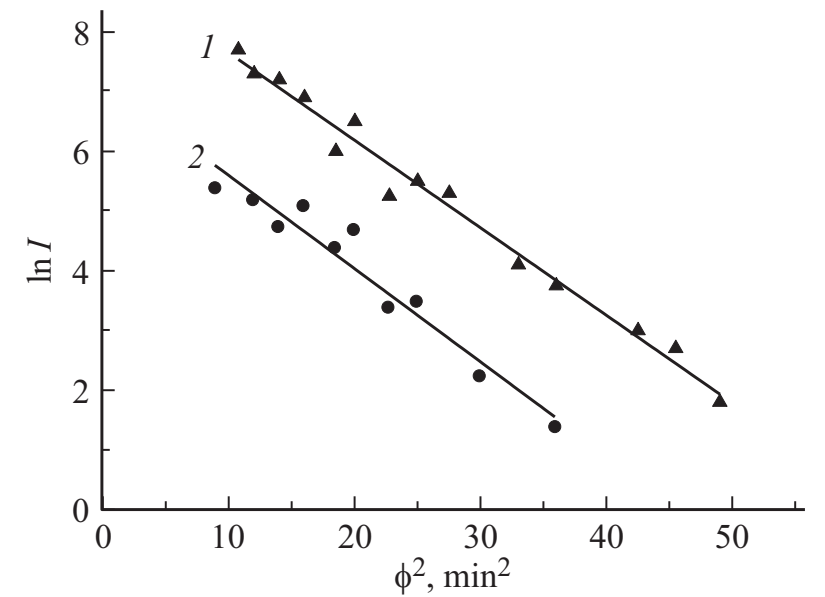

Рис. 6. Зависимость интенсивности I рентгеновских лучей от угла рассеяния $\varphi$ для УМЗ-титана до (1) и после (2) испытаний на ползучесть в координатах $\ln \mathrm{I}(\varphi)$.

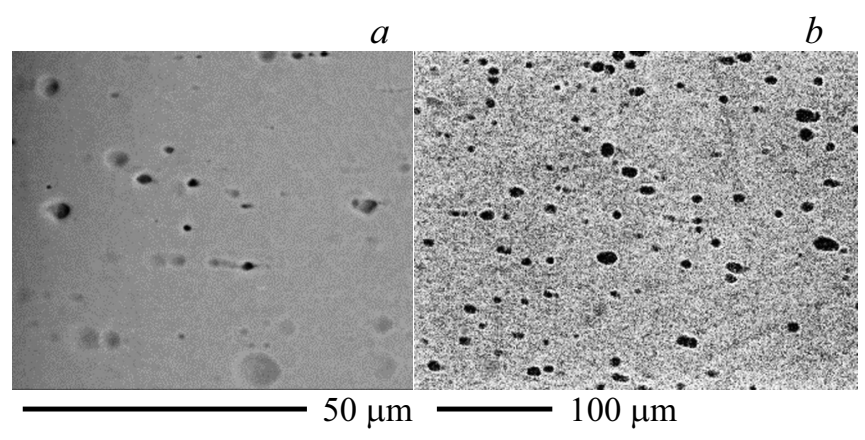

Рис. 7. Микропоры, образовавшиеся в образцах УМЗ ВТ1-0 $(a)$ и УМЗ-сплава $\mathrm{Al}+0.2 \% \mathrm{Sc}(b)$ после испытания на долговечность при растяжении в режиме ползучести.

Для определения размеров и концентрации образующихся при ИПД неоднородностей, которые, как показано ранее [17], являются нанопорами, полученные данные МРP перестраивались в координатах $\operatorname{lnI}-\varphi^{2}$ (рис. 6). Размер неоднородностей определялся согласно [32] из тангенса угла наклона прямых в координатах $\ln \mathrm{I}-\varphi^{2}$, а экстраполяция полученных прямых к нулевому углу, давала возможность оценить концентрацию нанопор. Проведенные оценки показали, что средний размер зафиксированных нанопор до и после испытания на долговечность в пределах точности измерения одинаков и составляет $\approx 25 \mathrm{~nm}$ (прямые в координатах $\operatorname{lnI}-\varphi^{2}$ практически параллельны). Это значение согласуется с данными, полученными для УМЗ-металлов, в том числе титана, ранее [11].

В отличие от размера нанопор, их концентрация (связанная с интенсивностью МРP) после разрушения при ползучести заметно уменьшается (рис. 5). Оценки показали, что если в „исходном“ (после ИПД) состоянии концентрации $1.5 \cdot 10^{11} \mathrm{~cm}^{-3}$, то после ползучести она $\approx 10^{10} \mathrm{~cm}^{-3}$, т.е. практически на порядок меньше.
При трактовке этого результата необходимо учесть, что использованный метод МРР не позволяет (в силу методических особенностей) фиксировать неоднородности размером в сотню и более нанометров. О том, что в процессе длительного нагружения в режиме ползучести такие более крупные несплошности образуются, свидетельствуют полученные в работе данные измерения разуплотнения. Так, для рассмотренных выше образцов УМЗ-титана „исходная“ (до испытания на ползучесть) пористость составляет $6 \cdot 10^{-4}$, а после разрыва она $\approx 9 \cdot 10^{-3}$, т.е. почти на 2 порядка больше.

Действительно данные электронной микроскопии показали, что в процессе ползучести изучаемых в работе образцов титана образуются микропоры размером $\approx 2 \mu$ и и более (рис. 7 ).

Таким образом, полученные данные свидетельствуют о том, что в процессе длительных испытаний в режиме ползучести концентрация фиксируемых методом МРР нанопор уменьшается почти на порядок и при этом образуются более крупные микропоры. Оценки показали, что количество микропор соизмеримо с числом „исчезнувших“ (не фиксируемых МРP) нанопор.

Рассмотренные данные дают основание полагать, что рост этих „исчезнувших“ нанопор и привел к образованию микропор. В этом случае возникает естественный вопрос - почему интенсивно растет только небольшая часть образовавшихся при ИПД нанопор. Информация, позволяющая прояснить этот вопрос, была получена после изучения эволюции в процессе ползучести при повышенной температуре размера зерен УМЗ-титана. Электронномикроскопические исследования показали, что после ВПП средний размер зерен в изучаемых в работе образцах титана $\approx 200 \mathrm{~nm}$ (рис. 8). После разрыва при испытании в режиме ползучести средний размер зерен оказался $\approx 1.5 \mu \mathrm{m}$, при этом наблюдались и более крупные зерна (рис. $8, b$ ). Следовательно, в процессе испытания размер зерен увеличился примерно на порядок; последнее привело к пропорциональному уменьшению площади границ зерен. Это обстоятельство, с учетом данных о нано и микропорах, дает основание полагать, что в микропоры развиваются только те нанопоры, которые остались на образовавшихся после рекристаллизации, границах. Очевидно, что после ИПД большинство нанопор (как и дислокаций, и неравновесных вакансий) локализуются в границах нано и субмикрокристаллических зерен. В процессе ползучести при повышенных температурах неравновесное состояние УМЗ-границ способствует их рекристаллизационному росту. (Отметим, что влияние неравновесного состояния границ зерен, которое и способствует их рекристаллизационному росту, наглядно видно при сравнении данных для обычного крупнозернистого титана, испытанного в том же режиме; размер зерен в этом случае практически не изменяется, рис. 9). Очевидно, что большая часть образовавшихся при ИПД нанопор оказывается при этом не на границах, а в объеме зерен; эти нанопоры практически не растут (или очень мало меняют свои 

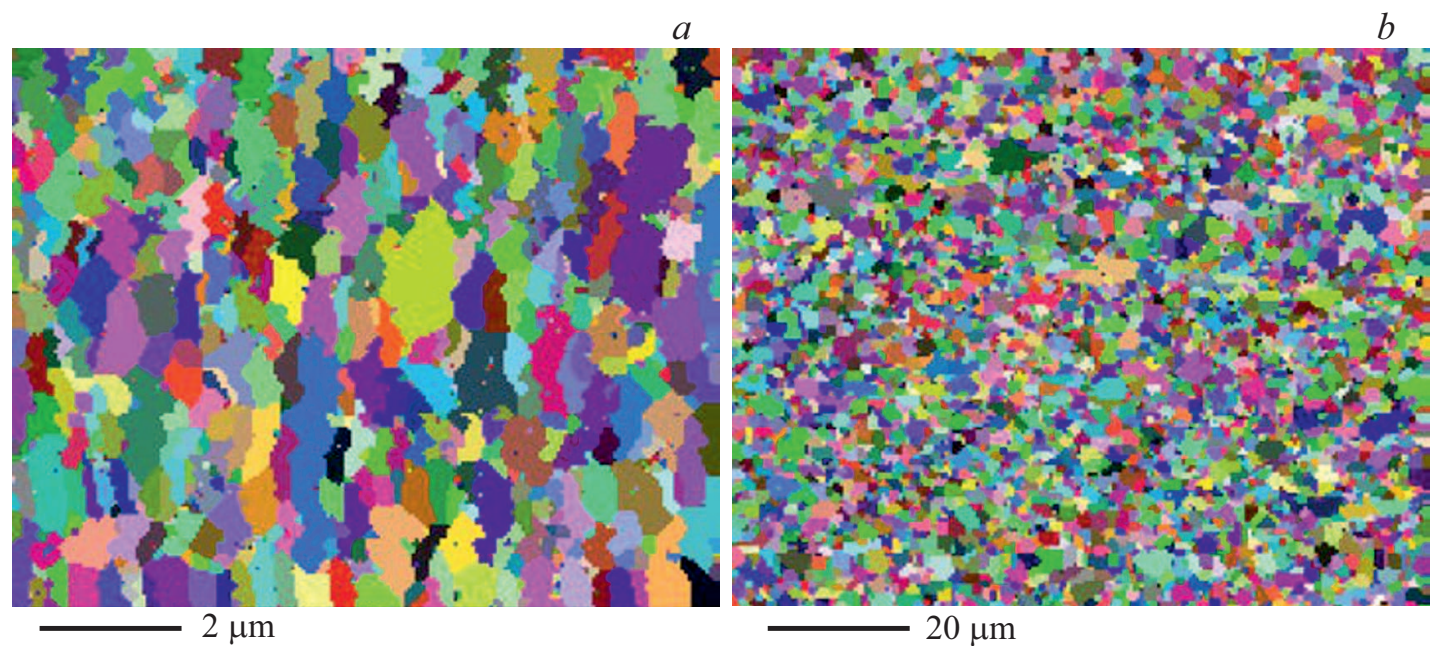

Рис. 8. Данные EBSD для ВT1-0 в УМЗ--состоянии до $(a)$ и после $(b)$ испытания на ползучесть при $T=673 \mathrm{~K}$ и $\sigma=100 \mathrm{MPa,}$ $t=1948 \mathrm{~h}$.

размеры). В то же время нанопоры, оставшиеся в границах интенсивно растут диффузионным механизмом. Этому способствует на порядки более высокая скорость диффузии в границах зерен по сравнению с объемом зерен [33]. Диффузионный механизм роста пор таких малых размеров представляется естественным [34]. При этом наряду с интенсивным диффузионным процессом развития пор возможно и их частичное залечивание, однако процесс увеличения размеров при исследованном режиме ползучести преобладает [35].

Нельзя, вероятно, исключить и влияние на переход нанопор в микропоры процесса зернограничного проскальзывания, однако диффузионный механизм роста пор с учетом рассмотренных выше аргументов, представляется более обоснованным.

Рассмотренные на примере УМЗ-титана закономерности изменения в процессе ползучести при повышенной температуре эволюции дефектной структуры носят, очевидно, достаточно общий характер. Действительно, качественно аналогичные данные были получены для Al и сплава $\mathrm{Al}+0.2$ wt.\% Sc. B [5,17] было показано, что размер зерен после РКУП в алюминии был $\approx 1 \mu \mathrm{m}$, а в сплаве $\mathrm{Al}-\mathrm{Sc} \approx 0.7 \mu \mathrm{m}$. В результате ползучесть при $473 \mathrm{~K}$ и напряжении $15 \mathrm{MPa}$ (Al) и $20 \mathrm{MPa}$ (Al-Sc) размер зерен вырос на порядок и более (до $\approx 8-20 \mu \mathrm{m}$ ) $[5,17,18,21-24]$. Проведенные в нашей работе методом МРР исследования показали, что средний размер нанопор $(\approx 15-25 \mathrm{~nm})$ в процессе ползучести алюминия практически не изменился, а их концентрация уменьшилась с $5 \cdot 10^{10} \mathrm{~cm}^{-3}$ в ,исходном“ (после РКУП) состоянии, до $\approx 2 \cdot 10^{9} \mathrm{~cm}^{-3}$ (после испытания в режиме ползучести). При этом величина разуплотнения алюминия после ползучести увеличилась $\mathrm{c} \approx 4 \cdot 10^{-3}$ до $\approx 10^{-2}$. Электронномикроскопические исследования зафиксировали, как и в титане, образование в процессе ползучести микропор размером от одного и более микрон (рис. 7).
Значения долговечности крупнозернистых („исходных“) и УМЗ-A1, $\mathrm{Cu}$ и их сплавов после испытания в режиме ползучести и разного числа проходов при РКУП

\begin{tabular}{c|c|c|c}
\hline \multirow{2}{*}{ Материал } & \multicolumn{3}{|c}{ Долговечность, hour } \\
\cline { 2 - 4 } & До РКУП & $\begin{array}{c}\text { После 1 прохода } \\
\text { РКУП }\end{array}$ & $\begin{array}{c}\text { После 8-12 } \\
\text { проходов РКУП }\end{array}$ \\
\hline $\mathrm{Al}$ & 4 & 1070 & 60 \\
$\mathrm{Al}-\mathrm{Sc}$ & 900 & 1400 & 7 \\
$\mathrm{Cu}$ & 6 & 450 & 40 \\
$\mathrm{Cu}-\mathrm{Zr}$ & 25 & 225 & 9
\end{tabular}

Таким образом, данные для УМЗ-алюминия и его сплава также свидетельствуют о том, что образовавшиеся при ИПД нанопоры, оставшиеся на границах зерен, развиваются в микропоры, т.е. являются „очагами“ развития разрушения в процессе ползучести при повышенной температуре.

Результаты изучения влияния РКУП на титан ВТ1-0 и сплав $\mathrm{Zr}-\mathrm{Nb}$ (рис. 1,2 ) свидетельствуют о том, что уже после первого прохода и перевода указанных материалов в УМЗ-состояние их механическая стабильность (долговечность) при испытании в режиме ползучести при повышенных температурах падает; с увеличением числа проходов этот негативный эффект увеличивается.

Анализ наших и литературных данных, однако показывает, что характер влияния степени ИПД (числа проходов при РКУП) на долговечность при испытании УМЗ-металлов в режиме ползучести носит более сложный характер [5,21-24].

После первого прохода и перевода в УМЗ-состояние долговечность ряда металлов и сплавов существенно растет, но лишь с увеличением числа проходов падает иногда даже ниже „исходного“ (до ИПД) состояния. В таблице приведены значения долговечности $\mathrm{Al}$ 

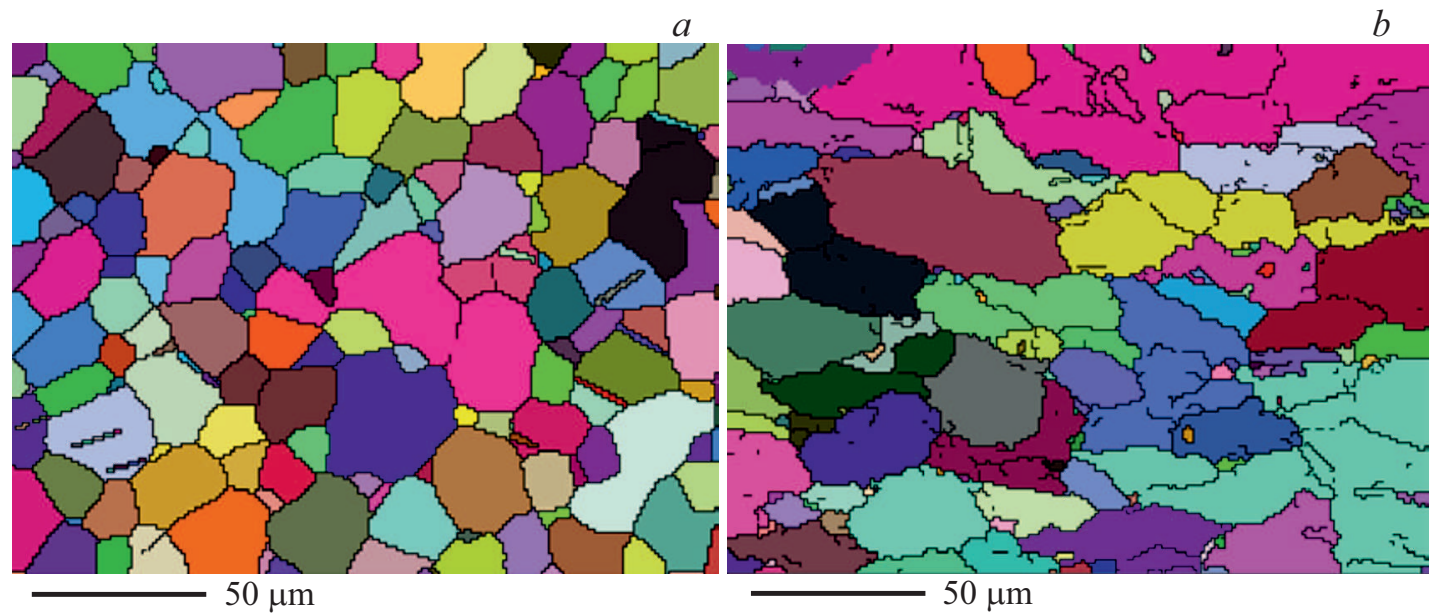

Рис. 9. Размер зерна ВТ1-0 (исходное крупнозернистое состояние) до (1) и после (2) испытаний на ползучесть при $T=673 \mathrm{~K}$ и $\sigma=150 \mathrm{MPa}$.

$(99.99 \%)$ и сплава $\mathrm{Al}+0.2 \% \mathrm{Sc}$, которые испытывались в режиме ползучести при $473 \mathrm{~K}$ и напряжении $15 \mathrm{MPa}(\mathrm{Al})$ и $20 \mathrm{MPa}(\mathrm{Al}-\mathrm{Sc})$ в исходном (до РКУП) состоянии и после 1 и 12 проходов при РКУП. В эту же таблицу включены данные по долговечности $\mathrm{Cu}(99.99 \%)$ и сплава $\mathrm{Cu}+0.2 \% \mathrm{Zr}$, которые испытывались в режиме ползучести при $473 \mathrm{~K}$ и напряжении $80 \mathrm{MPa}(\mathrm{Cu})$ и $673 \mathrm{~K}$ и напряжении $150 \mathrm{MPa}(\mathrm{Cu}-\mathrm{Zr})$. (Отметим, что сплав $\mathrm{Cu}-\mathrm{Zr}$ содержал дисперсные частицы $\mathrm{Cu}_{9} \mathrm{Zr}_{2}$, размером 10-50 nm [21-24], а сплав Al-Sc, как уже отмечалось, частицы $\left.\mathrm{Al}_{3} \mathrm{Sc}\right)$. Обращает на себя внимание, что хотя характер влияния степени ИПД на долговечность исследованных металлов и сплавов одинаков, количественные и даже качественные изменения долговечности у чистых УМЗ-металлов и их сплавов, содержащих дисперсные включения, существенно отличаются.

Действительно, как видно из таблицы, первый проход при РКУП ведет к существенному росту долговечности, но этот эффект у чистых металлов практически на порядок больше, чем у сплавов, содержащих наноразмерные включения. Последнее можно связать с тем, что разуплотнение в сплавах, связанное с повреждениями типа нанопор после ИПД значительно больше, чем в чистых металлах. Так, после первого прохода при РКУП разуплотнение в чистом $\mathrm{Al} \approx 2.5 \cdot 10^{-3}$, а в сплаве $\mathrm{Al}+0.2 \mathrm{wt} . \% \mathrm{Sc} \approx 5.5 \cdot 10^{-3}$. Как уже отмечалось в $[5,11]$ наноразмерные включения могут быть источником образования при ИПД высоких внутренних локальных напряжений, ведущих к образованию несплошностей. Микроскопические исследования, проведенные на сплаве $\mathrm{Al}-\mathrm{Mg}$ (например, $\mathrm{Al}-6.5 \% \mathrm{Mg}-0.6 \% \mathrm{Mn}$ ) показали, что после ИПД образуются поры и микротрещины, которые локализуются, в основном, в частицах второй фазы и на межфазных границах этих частиц. Образование этих несплошностей заметно влияет на развитие разрушения УМЗ-сплава [36,37]. Следует отметить, что наряду с негативной ролью включений в развитие нанопор и тре- щин при ИПД, наличие дисперсных включений оказывает стабилизирующее влияние на границы УМЗ-сплавов и их механические свойства при многих режимах их „кратковременного“ и длительного нагружения [8].

Из таблицы видно, что после 12 проходов при РКУП долговечность чистых УМЗ-металлов остается еще выше ,исходной“, а долговечность УМЗ-сплавов становится в разы меньше, чем долговечность этих же сплавов в крупнозернистом состоянии.

Аналогичное негативное влияние на развитие разрушения при длительном нагружении УМЗ-металлов и сплавов оказывает увеличение при РКУП доли большеугловых $\left(\varphi>15^{\circ}\right)$ границ, которые, как и частицы включений могут быть источниками высоких (образующихся при ИПД) локальных напряжений и способствовать развитию повреждаемости в процессе ползучести. Так для изучаемого в данной работе УМЗ-титана при переходе от 2 к 8 проходам РКУП она увеличилась с 30 до 59\%. Отметим, что увеличение доли большеугловых границ, также, как и уменьшение размеров зерен, с ростом степени ИПД (например, числа проходов РКУП) ведет к росту характеристик прочности при „кратковременном“, но негативно влияет при длительном нагружении. Вклад нанопористости и доли большеугловых границ в характеристик прочности при „кратковременном“ и длительном нагружении рассмотрены в $[19,20]$.

Таким образом, анализ рассмотренных случаев влияния РКУП на долговечность металлов и сплавов подтверждает вклад образования нанопористости в снижении механостабильности УМЗ-металлических материалов при их испытании в режиме ползучести и повышенной температуре. С учетом рассмотренных выше данных о влиянии числа проходов при РКУП на долговечность можно полагать, что снижение долговечности в титане ВТ1-0 и сплаве $\mathrm{Zr}+2.5 \mathrm{wt} . \% \mathrm{Nb}$ уже после первого прохода (рис. 1,2) обусловлено, очевидно интенсивностью образования нанопористости за счет их генерации 
при ИПД на имеющихся включениях. Этот эффект нивелирует рост долговечности за счет образования УМЗ-структуры.

\section{4. Заключение}

Установлено, что образовавшиеся при ИПД нанопоры являются „очагами“ развития микроразрушения в процессе ползучести УМЗ-металлов и сплавов при повышенных температурах.

Увеличение размеров нанопор происходит диффузионным механизмом, при этом интенсивно растут только те нанопоры, которые остались в границах зерен.

Анализируются особенности влияния числа проходов при РКУП на долговечность УМЗ-металлов и сплавов, содержащих дисперсные включения, на их долговечность при длительном нагружении в режиме ползучести.

\section{Финансирование работы}

Исследование выполнено за счет гранта Российского научного фонда (проект № 19-12-00221).

\section{Конфликт интересов}

Авторы заявляют, что у них нет конфликта интересов.

\section{Список литературы}

[1] М. Сегал, В.И. Резников, А.Е. Дробышевский, В.И. Копылов. Изв. АНСССР, Металлы 1, 115 (1981).

[2] M. Gleiter. Nanostruct. Mater. 1, 1 (1992).

[3] Р.А. Андреевский, А.М. Глезер. УФН 179, 4, 337 (2009).

[4] Р.3. Валиев, К.В. Александров. Наноструктурные металлы, полученные интенсивной пластической деформацией. Логос, М. (2002). 272 с.

[5] В.И. Бетехтин, V. Skleniska, I. Saxl, Б.К. Кардашев, А.Г. Кадомцев, М.В. Нарыкова. ФТТ 52, 8, 1517 (2010).

[6] M. Kvapilova, V.I. Kopylov, S.A. Nikulin, S.V. Dobatkin. Acta Phys. Polonica A 122, 477 (2012).

[7] В.И. Бетехтин, J. Dvorak, А.Г. Кадомцев, Б.К. Кардашев, М.В. Нарыкова, Г.К. Рааб, V. Sklenicka, С.Н. Фаизова. ПЖТФ 41, 2, 58 (2015).

[8] В.И. Бетехтин, Ю.Р. Колобов, V. Sklenicka, А.Г. Кадомцев, M.В. Нарыкова, J. Dvorak, Б.К. Кардашев. ЖТФ 85, 1, 66 (2015).

[9] R.A. Andrievski, A.V. Khatchoyan. Nanomaterials in Extreme Environments. Fundamentals and Applications. Springer Int. Publ., Switzerland (2016). 107 p.

[10] Р.А. Андриевский. Успехи химии 83, 4, 365 (2014).

[11] В.И. Бетехтин, V. Sklenicka, А.Г. Кадомцев, Ю.Р. Колобов, М.В. Нарыкова. ФТТ 59, 5, 535 (2017).

[12] M. Kawasaki, V. Sklenicka, T.G. Langdon. J. Mater. Sci. 45, 271 (2010).

[13] В.Ф. Терентьев, С.В. Добаткин, С.А. Никулин, В.И. Копылов, С.О. Рогачев, И.О. Банных. Деформация и разрушение материалов 8, 26 (2010).

[14] J. Dvorak, V. Sklenicka, V.I. Betekhtin, A.G. Kadomtsev, P. Kral, M. Svoboda. Mater. Sci. Eng. A 584, 103 (2013).
[15] В.И. Бетехтин, Ю.Р. Колобов, М.В. Нарыкова, Е.В. Голосов, Б.К. Кардашев, А.Г. Кадомцев. ЖТФ 81, 11, 58 (2011).

[16] Yu.R. Kolobov. Nanotechnologies in Russia 4, 11-12, 758 (2009).

[17] V.I. Betekhtin, A.G. Kadomtsev, V. Sklenicka, I. Saxl. ФTT 10, 1787 (2007).

[18] J. Dvorak, V. Sklenicka, V.I. Betekhtin, A.G. Kadomtsev, P. Kral, M. Kvapilova, M. Svoboda. Mater. Sci. Eng. A 584, 103 (2013).

[19] В.И. Бетехтин, А.Г. Кадомцев, V. Sklenicka, М.В. Нарыкова. ПЖТФ 37, 20, 75 (2011)

[20] V. Sklenicka, V.I. Betekhtin, A.I. Petrov, A.G. Kadomtsev, K. Kucharova. Scripta Mater. 25, 2159 (1991).

[21] V. Sklenicka, J. Dvorak, M. Svoboda. Mater. Sci. Eng. A 387-389, 696 (2004).

[22] V. Sklenicka, J. Dvorak, P. Kral, Z. Stronawska, M. Svoboda. Mater. Sci. Eng. A 410-411, 408 (2005).

[23] I. Saxl, V. Sklenicka, L. Ilusova, M. Svoboda, J. Dvorak, P. Kral. Mater. Sci. Eng. A 503, 82 (2009).

[24] V. Sklenicka, J. Dvorak, P. Kral, M. Svoboda, M. Kvapilova, T.G. Langdon. Mater. Sci. Eng. A 558, 403 (2012).

[25] R. Lapovok, D. Tomus, J. Mang, Y. Estin, T.C. Lowe. Acta Mater. 57, 2909 (2009).

[26] J. Ribbe, G. Schmitz, D. Gundarev, Y. Estin, Y. Amouyal, S.V. Divinski. Acta Mater. 61, 5477 (2013).

[27] S.V. Divinski, G. Reglitz, I.S. Golovin, M. Peterlechner, R. Lapovok, Y. Estin, G. Wilde. Acta Mater. 82, 11 (2015).

[28] В.Н. Перевзенцев, А.С. Пупынин, А.Е. Огородников. ЖТФ 88, 10, 1539 (2018).

[29] J. Čizek, M. Janecek, O. Sbra, R. Kuzel, Z. Barnovska, I. Prochazka, S.V. Dobatkin. Acta Mater. 59, 2322 (2011).

[30] В.В. Мишакин, В.Н. Перевезенцев, М.Ю. Щербань, В.А. Клюшников, Т.А. Грачева, Т.А. Кузьмичева. Дефектоскопия 6, 57 (2015).

[31] S.V. Divinski, G. Reglitz, H. Rosner, Y. Estrin, G. Wild. Acta Mater. 59, 1974 (2011).

[32] A. Guinier, G. Fournet. S-mall-Angle Scattering of X-rays. J. Willey, N.Y. (1955).

[33] Yu.R. Kolobov, G.P. Grabovetskaya, M.B. Ivanov, A.R. Zhilyaev, R.Z. Valiev. Scripta Mater. 44, 873 (2001).

[34] D.A. Miller, T.G. Langdon. Metallurg. Trans. A 10, 1969 (1979).

[35] П.Г. Черемской, В.В. Слезов, В.И. Бетехтин. Поры в твердом теле. Энергоатомиздат, М. (1990). 345 с.

[36] M.B. Markushev, M.Y. Murashkin. Mater. Sci. Eng. A 367, 1-2, 234 (2004).

[37] М.В. Маркушев. Материалы Межд. конф. „Прочность и разрушение материалов и конструкций“. Оренбург (2008). T. 1. C. 162.

Редактор Т.Н. Василевская 